\section{LEARN MORE IN MANCHESTER}

Visit stand B30 at this year's British Dental Conference and Exhibition in Manchester on 26-28 April and discover how Sensodyne Repair \& Protect can actually help repair your patients' exposed dentine. With twice daily brushing the NovaMin bioactive technology builds a substantive hydroxyapatite-like layer over exposed dentine and within dentine tubules, to help prevent sensitivity.

Trial size packs and information on GSK's other oral care brands such as Aquafresh and Corsodyl will also be available, including details of the Corsodyl Gum Care Pack, which is available free to practices.

For further information on GSK products visit www.gsk.com

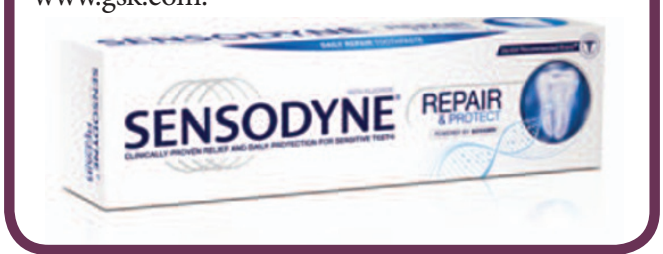

\section{WHITENING AND LESS ABRASIVE}

Beverly Hills Formula whitening toothpaste is less abrasive than other leading brands of both whitening and regular toothpastes, scoring as low as 93 on the RDA (relative dentine abrasivity) table, whilst some leading competitors have levels as high as 147 .

Any toothpaste with a value over $100 \mathrm{RDA}$ is considered to be abrasive. Highly abrasive toothpastes can wear away tooth enamel so the dentine becomes more visible and teeth become more yellow and also sensitive to hot and cold.

Beverly Hills Formula's low abrasion range is capable of protecting against tooth decay whilst restoring patients' teeth to a natural white colour.

Email info@beverlyhillsformula.com or visit www.beverlyhillsformula.com.
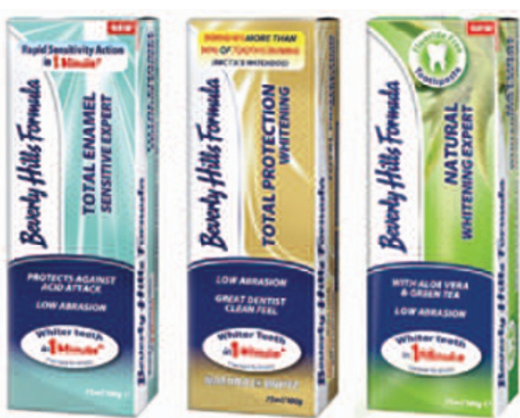

\section{ORAL CANCER SCREENING DEVICE}

New from DentalEZ is the Identafi multi-spectral oral cancer screening device.

Identafi helps those in the front line of detection to identify biochemical and morphological changes in the cells of the mouth, throat, tongue and tonsils.

The detection is made through the processing of optical fluorescence and reflectance in certain body tissues, using this small portable device.

In the UK alone in 2008 there were 5,790 cases of an oral cancer according to the British Dental Health Foundation. Because of the high mortality rate, due to late diagnosis, it is essential patients are educated about this deadly disease.

Often the signs and symptoms are missed by the naked eye so this device can help in the screening process.

Telephone 01442269301 or visit www.dentalez.com or www.identafi.net for more information.

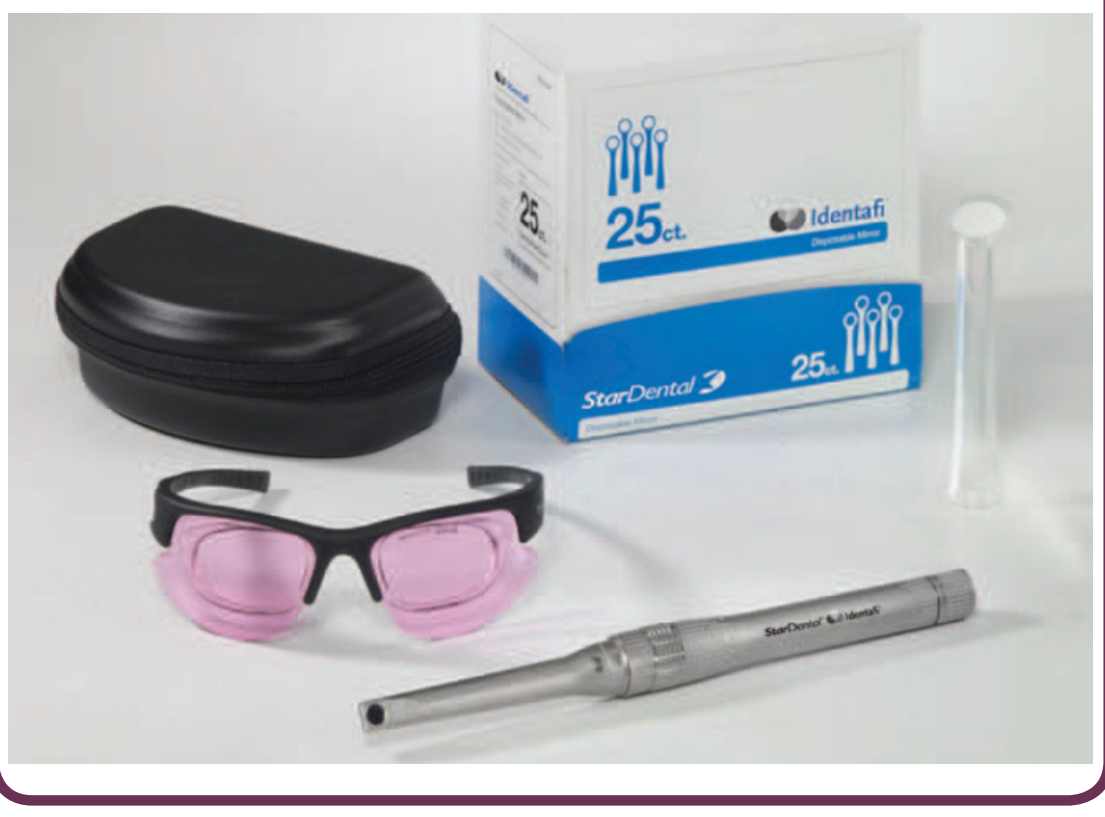

\section{EFFECTIVELY INTERFERING WITH BACTERIA}

Periproducts' product range not only includes the highly effective and clinically researched RetarDEX alcohol free oral rinse, oral spray and SLS free toothpaste, but also an extensive range of interdental products, a tongue cleanser and an ionic action toothbrush.

The patented ingredient CloSYS II in the RetarDEX range interferes with the formation of biofilms and is antibacterial, antiviral and antifungal, killing both the aerobic and anaerobic bacteria

associated with plaque, tooth decay and gum disease. Independent clinical tests have proven that the active ingredient eliminates bad breath for at least eight hours and that both the toothpaste and oral rinse whiten teeth within two weeks by gently removing organic stains such as tea, coffee, tobacco and red wine.

The Interproximal Denti-Brushes are designed with 'Pivot Technology' to minimise potential breakage.

For further information call 0208868 1500 or visit www.periproducts.co.uk.

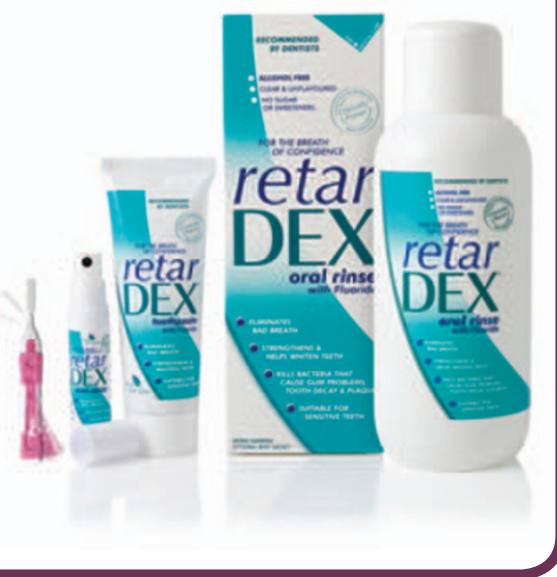

If you would like to promote your products or services direct to the dental industry through VITAL UPDATE telephone Andy or Grainne on 02078434785. 